
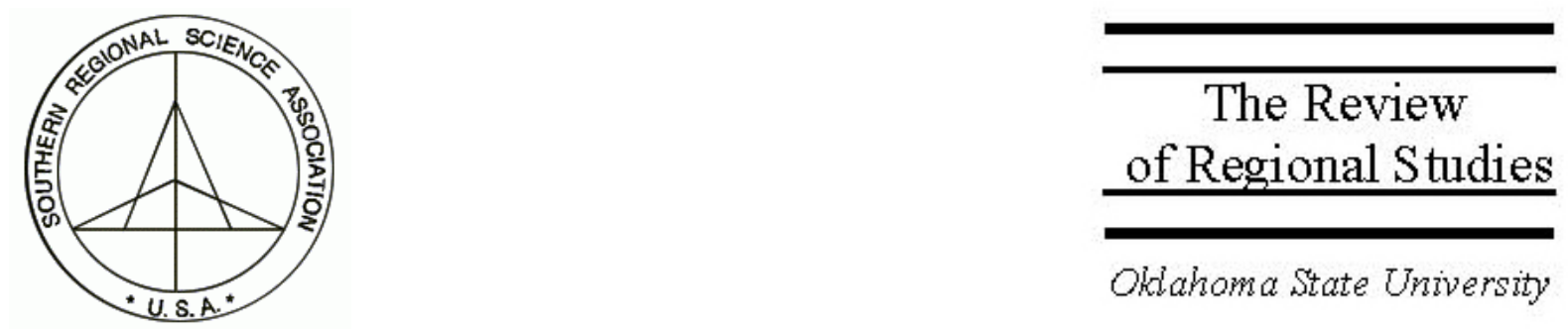

\title{
The Time Pattern of Internal Migration: Human Capital Meets Job Matching*
}

\author{
Jeremiah Allen \\ Department of Economics, University of Lethbridge, \\ Lethbridge,AB, T1K3M4,Canada,email:allenj@uleth.ca
}

\begin{abstract}
A human capital model of migration that includes location-specific capital and job search is integrated with job-matching/flows approach to labor markets. This generates a model that is consistent with the observed pro-cyclicality of new migration. Unlike all previous models, this model not only explains, it predicts the observed counter-cyclicality of return migration.
\end{abstract}

\footnotetext{
* I am grateful to B. Curtis Eaton, Gary L. Hunt, and anonymous referees for helpful comments. Any errors are mine.
} 


\section{INTRODUCTION}

The recent development of job-matching models of labor markets has led some observers to suggest that fundamental problems exist between human capital theory and the timing of labor mobility. ${ }^{1}$ Noting that unemployment differentials are counter-cyclical and that, as is welldocumented, internal (new) migration is pro-cyclical, two observers state, "The standard economic model of migration, based on human capital theory, . . .offers no explanation of the time series behavior of aggregate migration, and in particular appears inconsistent with the observation that migration flows often fall when unemployment differentials widen" (Jackman and Savouri 1992, p. 1433). ${ }^{2}$ If true, this would be distressing. The human capital "revolution," like many good scientific revolutions, was simple: it was just a restatement of fundamental economic rationality, adding a correct treatment of time. In human capital models of migration, individuals make migration choices to maximize discounted, expected, lifetime utility. If it is failing, something is wrong at a fundamental level.

Fortunately, it's not. Jackman and Savouri's comment is based on a too-simple conception of the human capital model. Here I use two additions to the simple human capital model, neither new: the importance of location-specific capital (LSK), and the necessity of job search. I integrate this model with job-matching. The integrated model easily accommodates the observations of pro-cyclicality of (new) migration.

What may be more important, the integrated model has the virtue of explaining the time pattern of internal return migration. With internal migration, nearly three-quarters of all initial, new, moves are followed by a second, repeat, move. Roughly two-thirds of repeat moves are second new moves, or onward moves, the other third are moves back to the region from which the initial move was made, or return moves. ${ }^{3}$ Return migration is counter-cyclical. Although this phenomenon is an important component of "the times series behavior of aggregate migration," all models to date, including job-matching, are not only silent about it, they have no way to accommodate it. The model here not only accommodates this observation, it predicts it.

\section{THE MODEL}

The national labor market is divided into $n$ regions, denoted $J, J=1, n$. Individuals are utility maximizers and choose to live in the region that maximizes their utility. Utility in any period is

\footnotetext{
${ }^{1}$ Jackman and Savouri (1992). For details of job matching models see Blanchard and Diamond (1990 and 1992) (where it is called the "flows approach") and Padoa-Schioppa (1991).

${ }^{2}$ For the documentation on the pro-cyclicality of new migration see Vanderkamp (1968); Greenwood, Hunt, and McDowell (1986); Pissarides and Wadsworth (1989); the papers in Padoa-Schioppa (1991); Jackman and Savouri (1992); and Westerlund (1997). It should be clear, but here only internal - intra-national - migration is being modeled and described. International migration, especially international return migration, may behave differently.

${ }^{3}$ These are very rough North American figures. Estimates of repeat migration suffer from the fact that good longitudinal data are scarce and rarely used. DaVanzo and Morrison (1982), using longitudinal data for the U.S., found that over 75 percent of all moves are repeat moves and that about one-third of those were return. Vanderkamp (1972), using one-year intervals in Canada, found that about one-third of primary migrants made a return move in the following year. Newbold (1997), using five-year intervals for both Canada and the U.S., found that about half of primary migrants made a repeat move; about one-third of these were return in the U.S., about 60 percent were return in Canada. Five-year intervals fail to capture many repeat moves, thus the "three-quarters" in the text.
} 
an increasing function of consumption in that period. Consumption is the sum of two components: 1) consumption of tangible goods and services and 2) "consumption" of intangible goods and services ("psychic" income). The stock from which location-dependent intangible consumption flows is LSK. The existence of LSK and its importance to migration decisions is wellestablished and explains a large number of empirical observations, some quite subtle. ${ }^{4}$

LSK is of two types. The first type accumulates with time in a region and depreciates after leaving the region. Examples include knowledge of a region: knowing the spatial distribution of relative prices, consumption opportunities, and job opportunities; knowing which areas are safer, which schools are better, which transportation routes faster; and knowing what and where spouse's and/or children's employment opportunities are. This type of LSK also includes ties to the region such as family and a stock of like people with whom one enjoys interacting.

The second type of LSK is relatively constant in time and is usually referred to as "amenities." Examples include climate, access to recreation opportunities, the availability of interesting restaurants and other services, and low crime rates. The value of these will vary among individuals. LSK, therefore, is specific to individuals as well as to regions. The flow of consumption from LSK for any individual, in any period, at various regions, is denoted $L_{t}^{i}(J)$. $L_{t}{ }^{i}(J)$ is increasing in the individual's time spent at $J$ and decreasing in time spent away from $J$.

Money income is the sum of per-period employment earnings, $E_{t}^{i}(J)$, other per-period income, $F_{t}^{i}(J)$, and interest earned on net wealth, $r \cdot W_{t}^{i}$. Employment is, trivially, location-dependent. The largest element of "other income" for many individuals is spouse's earnings, which can also be location-dependent. There are costs associated with moving; here these are treated (implicitly) as subtractions from net wealth.

Total money income, therefore, is location-dependent and for individual, $i$, in any region, $J$, in any period, $t$, is:

$(1-\mathrm{A}) \quad Y_{t}^{i}(J)=\left[E_{t}^{i}(J)+F_{t}^{i}(J)+r \cdot W_{t}^{i}\right]$.

Consumption of tangibles for $i$ in that period is $\left[Y_{t}^{i}(J)-\Delta W_{t}^{i}\right] / P_{t}(J)$, where $P_{t}(J)$, is Prices, also location-dependent. Total consumption for $i$ in period $t$ is the sum of the consumption of tangibles and the consumption flow from LSK:

$$
C_{t}^{i}(J)=\left\{\left[Y_{t}^{i}(J)-\Delta W_{t}^{i}\right] / P_{t}(J)\right\}+L_{t}^{i}(J)
$$

The utility of any individual in any region in any period is $\mathrm{u}^{i}\left[C_{t}^{i}(J)\right]$, where $\mathrm{u}^{i}()$ is a utility function that is increasing and concave in $C$, and different for different individuals. Many of the arguments of $C_{t}^{i}(J)$ are uncertain or unknown, so many of the arguments of $\mathrm{u}^{i}()$ are expected values. Since the issue is labor market migration, I consider only expected utility to retirement

\footnotetext{
${ }^{4}$ Because the question here is the cyclical pattern of migration, here I detail only LSK's effect on that. For details of other effects, see DaVanzo (1981) and Herzog and Schlottman (1983) and the references there.
} 
age. ${ }^{5}$ Each individual expects to retire after $z^{i}$ periods. Since the ages of individuals vary at any real time, $z^{i}$ differs among individuals.

Each individual is characterized by $n$ "state-dependent" expected lifetime utility functions, $\mathrm{U}^{i}(J), J=1, n$, with regions as "states":

$$
\mathrm{U}^{i}(J)=\sum_{t=0}^{z^{i}} \mathrm{u}^{i}\left[C_{t}^{i}(J) \bullet \delta_{t}\right], \quad J=1, n,
$$

where $\delta$ is the discounting factor, here assumed the same for all individuals.

Job search is added to the model, which allows integration with job-matching. ${ }^{7}$ Labor market migration is of two types: an individual finds a job in a region different from her current residence and migrates, or an individual migrates to search for a job. The first is trivially procyclical. So here I develop a model of individuals migrating to search and show that it can be pro-cyclical. Search takes time. The conventional job search approach assumes the searcher knows the shape of the wage distribution and chooses a "stopping value" - the reservation wage. This strictly implies that the searcher has an expected search time in each region; denote this expected search time as $q^{i}(J){ }^{8}$

Two special regions must be differentiated. All individuals are somewhere; denote the region where they are as $\dot{J}^{i}$. Denote the potential destination with the individual's maximum $\mathrm{U}^{i}(J), J \neq \dot{J}^{i}$, as $\hat{J}^{i}$. Equations (2) can be rewritten as $n$ equations in two parts, recognizing search:

$$
\begin{aligned}
& \mathrm{U}^{i}\left(\dot{J}^{i}\right)=\sum_{t=0}^{q^{i}\left(J^{i}\right)} \mathrm{u}^{i}\left[C_{t}^{i}\left(\dot{J}^{i}\right) \cdot \delta_{t}\right]+\sum_{t=q^{i}\left(J^{i}\right)}^{z^{i}} \mathrm{u}^{i}\left[C_{t}\left(\dot{J}^{i}\right) \cdot \delta_{t}\right], \\
& \mathrm{U}^{i}(J)=\sum_{t=0}^{q^{i}(J)} \mathrm{u}^{i}\left[C_{t}^{i}(J) \cdot \delta_{t}\right]+\sum_{t=q^{i}(J)}^{z^{i}} \mathrm{u}^{i}\left[C_{t}^{i}(J) \cdot \delta_{t}\right], \quad J \neq \dot{J}^{i}
\end{aligned}
$$

\footnotetext{
${ }^{5}$ The location choices of retired people will differ considerably from those of people active in the labor market. For evidence that this is so, see Clark, Knapp, and White (1996).

${ }^{6}$ The first use of state-dependent utility functions was by Eisner and Strotz (1961). Karni (1985) has a fine summary. State-dependent utility functions are normally used in situations characterized by uncertainty, so their use here is not entirely conventional. However it is a sensible extension of the idea, and, indeed, once locationdependent characteristics enter utility functions, it seems the only sensible way to model the choices faced by potential migrants.

${ }^{7}$ The basic principle of job search was introduced by Stigler (1962). See Mortensen (1986) and Devine and Kiefer (1990) for good summaries. Job search was first incorporated into a migration model in Yezer and Thurston (1976) and Allen (1979). McCall and McCall (1987) has a good formal statement of a migration model with job search.

${ }^{8}$ Seeing these $q$ s in the model, one reader called this a "Harris/Todaro" (HT) model. But the distinguishing characteristic of HT models is not job search, it is institutional dualism in the urban area of rural/urban migration (usually in the Third World), with an institutionally fixed wage the "formal" urban sector (Harris and Todaro 1970). It's true that HT models use the expected time of urban job search as a cost of migration, but that cost has been implicit in labor models since Stigler (1962). The model here simply adds conventional job search to human capital. It uses neither institutional dualism nor a fixed wage and is primarily about internal migration in developed countries. It is, therefore, quite outside the tradition of HT models.
} 
Only $\hat{J}^{i}$ plays a role, so one of the equations $3-\mathrm{B}$ is special and is denoted:

$(3-\hat{\mathrm{B}}) \mathrm{U}^{i}\left(\hat{J}^{i}\right)=\sum_{t=0}^{q^{i}(\hat{J})} \mathrm{u}^{i}\left[C_{t}^{i}\left(\hat{J}^{i}\right) \cdot \delta_{t}\right]+\sum_{t=q^{i}(\hat{J})}^{z^{i}} \mathrm{u}^{i}\left[C_{t}^{i}\left(\hat{J}^{i}\right) \cdot \delta_{t}\right] \cdot{ }^{9}$

For ease of presentation, I refer to the summations of equations (3-A) and $(3-\hat{B})$ by their upper-case letter and position, so A1 is $\sum_{t=0}^{q^{i}\left(\dot{J}^{i}\right)} \mathrm{u}^{i}\left[C_{t}^{i}\left(\dot{J}^{i}\right) \bullet \delta_{t}\right]$ and $\hat{\mathrm{B}} 2$ is $\sum_{t=q^{i}(J)}^{z^{i}} \mathrm{u}^{i}\left[C_{t}^{i}\left(\hat{J}^{i}\right) \bullet \delta_{t}\right]$, etc. I refer to the units being summed in equations $(3-\mathrm{A})$ and $(3-\hat{\mathrm{B}})$ by their lower-case letter and position, so $a 1$ is $\mathrm{u}^{i}\left[C_{t}^{i}\left(\dot{J}^{i}\right) \bullet \delta_{t}\right]$ and $\hat{b} 2$ is $\mathrm{u}^{i}\left[C_{t}^{i}\left(\hat{J}^{i}\right) \bullet \delta_{t}\right]$, etc. Thus the 1 components of the utility functions represent the contributions to utility before and during search, and the _2 components represent the expected contributions to utility following successful search.

\section{RESULTS}

\subsection{The Pro-cyclicality of New Migration}

Most individuals will not have recently made a move, and LSK accumulates with time in a region. So for most individuals most of the time, the value of flows from LSK where they are, $L_{t}^{i}\left(\dot{J}^{i}\right)$ is substantially larger than $L_{t}^{i}\left(\hat{J}^{i}\right)$. For people who have not recently migrated, this causes $a 1$ to be enough greater than $\hat{b} 1$ and, therefore, A1 to be enough greater than $\hat{\mathrm{B}} 1$, to make $\mathrm{U}^{i}\left(\dot{J}^{i}\right)>\mathrm{U}^{i}\left(\hat{J}^{i}\right)$.

Everyone begins at $\dot{J}^{i}$, so initially $\mathrm{U}^{i}\left(\dot{J}^{i}\right)>\mathrm{U}^{i}\left(\hat{J}^{i}\right)$. As real time proceeds, individuals accumulate information, the economy goes through dynamic structural changes, and the economy experiences business cycles. All of these will change values of $\mathrm{U}^{i}\left(\dot{J}^{i}\right)$ and $\mathrm{U}^{i}\left(\hat{J}^{i}\right)$, and they can therefore trigger a move. But because the focus here is only on the cyclical aspects of migration, only changes in $\mathrm{U}^{i}\left(\dot{J}^{i}\right)$ and $\mathrm{U}^{i}\left(\hat{J}^{i}\right)$ caused by business cycles are considered.

In job-matching, hires $(H)$ is the variable representing the cycle. "Hires" is pro-cyclical. The $q \mathrm{~s}$ are decreasing in $H$, so in the aggregate, the $q$ s are counter-cyclical; thus both $\mathrm{U}^{i}\left(\hat{J}^{i}\right)$ and $\mathrm{U}^{i}\left(\dot{J}^{i}\right)$ are increasing in $H$. Earnings differentials can exist between regions, which causes $\hat{b} 2$ to be greater than $a 2$. For some individuals, this will cause there to be values of $q^{i}(\dot{J})$ and $q^{i}(\hat{J})$ that make $\hat{\mathrm{B}} 2$ enough greater than $\mathrm{A} 2$ to cause $\mathrm{U}^{i}\left(\hat{J}^{i}\right)>\mathrm{U}^{i}\left(\dot{J}^{i}\right)$. The integrated model allows a description of how this happens.

\footnotetext{
${ }^{9}$ Which region is actually $\hat{J}$ will vary over time. But at the time of a new move only one region can be the destination, and that is denoted $\hat{J}$.
} 
During an expansion, as $H$ rises and the $q$ s fall, units of $a 2$ and $\hat{b} 2$ are being added to A2 and $\hat{\mathrm{B}} 2$. Since $\hat{b} 2>a 2, \hat{\mathrm{B}} 2$ grows faster than does A2. Simultaneously, units of $a 1$ and $\hat{b} 1$ are being subtracted from $\mathrm{A} 1$ and $\hat{\mathrm{B}} 1$. Since $a 1>\hat{b} 1$, A 1 falls faster than does $\hat{\mathrm{B}} 1$. Both effects cause $\mathrm{U}^{i}\left(\hat{J}^{i}\right)$ to increase faster than $\mathrm{U}^{i}\left(\dot{J}^{i}\right)$ as $H$ increases. For labor market migrants, the two cross at some value of $H$. At this point the "weight" of expected higher earnings in $\mathrm{U}^{i}\left(\hat{J}^{i}\right)$ starts to dominate the "weight" of LSK in $\mathrm{U}^{i}\left(\dot{J}^{i}\right)$ and the individual migrates-to-search. This is shown on Figure 1. There $\alpha^{i}$ is the value of $H$ that induces migration-to-search by individual $i$.

There is a continuum of individuals, each with an $\alpha^{i}$. The pro-cyclicality of aggregate (new) migration-to-search simply means that the $\alpha^{i}$ s are increasing in $H$. As $H$ rises, the volume of new migration-to-search rises; and as $H$ falls, the volume of new migration-to-search falls. New migration to search is pro-cyclical. As noted above, migration to a job found in a region in which the migrant did not reside during search is, trivially (tautologically), increasing in $H$. Thus, internal labor market new migration can be (and is) pro-cyclical.

\section{FIGURE 1}

Utility Functions as Hires Increase

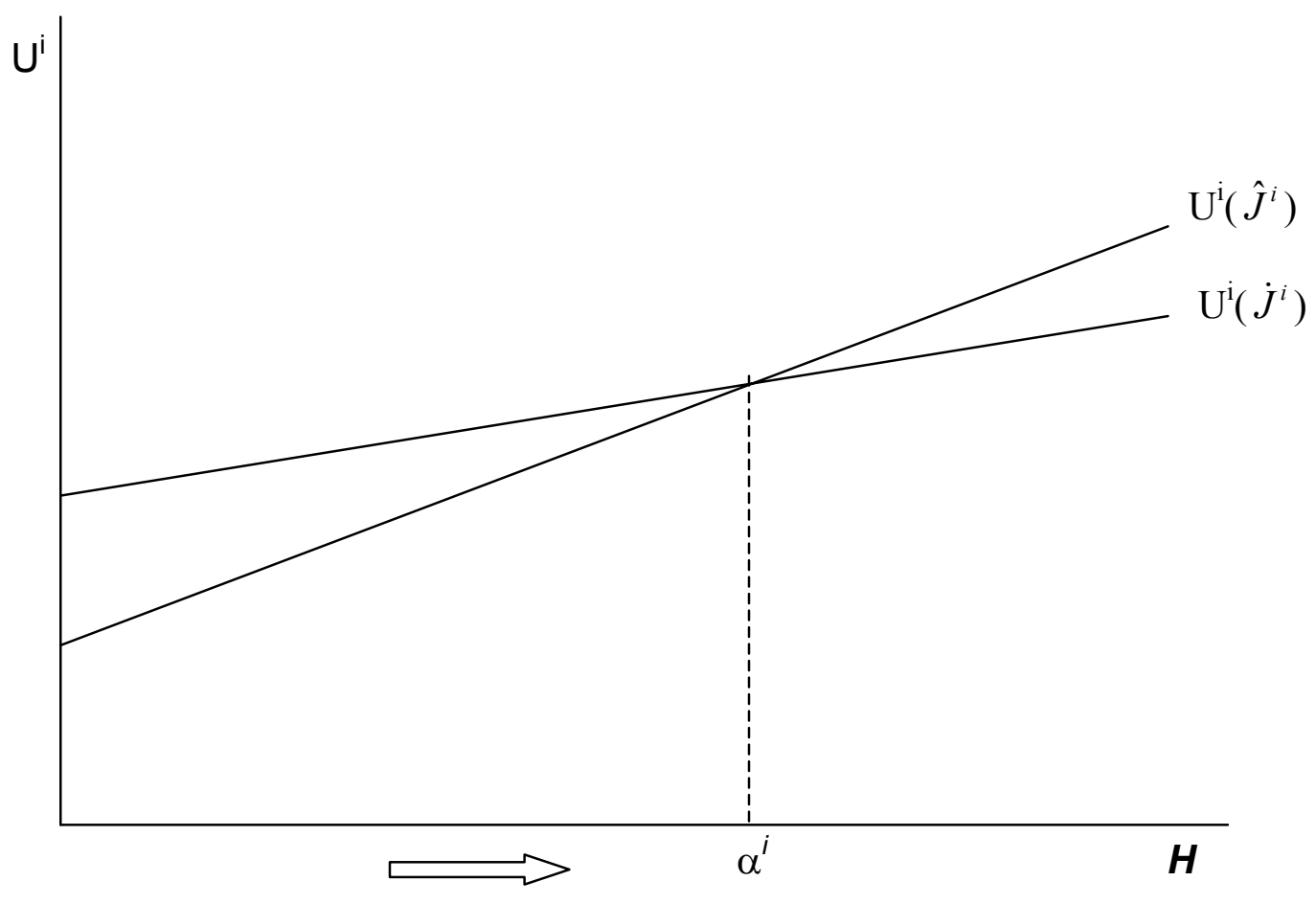




\subsection{The Flip Side: The Counter-Cyclicality of Return Migration}

Curiously, despite recent attention to the time pattern of migration and a burgeoning literature on repeat migration, only five published studies have looked at the time pattern of internal return migration, and only one of these is especially recent. Three are of Canada, one of the U.K., and one of migration between Finland and Sweden, which is a single integrated labor market. All but one find return migration to be strongly counter-cyclical. ${ }^{10}$

In the discussion that follows, $\dot{J}^{i}$ remains the region the migrant moved from. $\hat{J}^{i}$, which was the potential destination, is now the actual destination and is where the migrant now resides. A third region is differentiated: $\widetilde{J}^{i}$ is the region with the individual's maximum $\mathrm{U}^{i}(J), J \neq \dot{J}^{i}$, $J \neq \hat{J}^{i}$. LSK accumulates where the individual resides and depreciates in the region she has left, so $L_{t}^{i}\left(\dot{J}^{i}\right)$ falls after the initial move, and $L_{t}^{i}\left(\hat{J}^{i}\right)$ rises. Nevertheless, for many new migrants, $L_{t}^{i}\left(\dot{J}^{i}\right)$ will remain above $L_{t}^{i}\left(\hat{J}^{i}\right)$ for some time, well above it for those new migrants for whom $\dot{J}^{i}$ is "home." In addition, the size of return migration relative to onward migration shows that, for many individuals, "recently" after a new move $\mathrm{U}^{i}\left(\dot{J}^{i}\right)$ remains greater than $\mathrm{U}^{i}\left(\widetilde{J}^{i}\right)$ because of continuing high values of LSK at $\dot{J}^{i}$.

I operationally define "recent" to mean those periods for which $L_{t}^{i}\left(\dot{J}^{i}\right)>L_{t}^{i}\left(\hat{J}^{i}\right)$ and $L_{t}^{i}\left(\dot{J}^{i}\right)>L_{t}^{i}\left(\widetilde{J}^{i}\right)$. Potential return migrants are those recent new migrants for whom there exist values of $\mathrm{A} 1$ and $\hat{\mathrm{B}} 1$, and values of the $q$ s that can cause $\mathrm{U}^{i}\left(\dot{J}^{i}\right)>\mathrm{U}^{i}\left(\hat{J}^{i}\right)$. (Obviously, new migrants who are still searching, so their $E_{t}^{i}\left(\hat{J}^{i}\right)$ is zero, are more "at risk" to become repeat migrants.)

During a contraction in the economy, as $H$ falls and the $q$ s rise, units of $a 1$ and $\hat{b} 1$ are being added to $\mathrm{A} 1$ and $\hat{\mathrm{B}} 1$. Since $a 1>\hat{b} 1, \mathrm{~A} 1$ grows faster than does $\hat{\mathrm{B}} 1$. Simultaneously units of $a 2$ and $\hat{b} 2$ are being subtracted from $\mathrm{A} 2$ and $\hat{\mathrm{B}} 2$. Since $\hat{b} 2>a 2, \hat{\mathrm{B}} 2$ falls faster than does $\mathrm{A} 2$. Both effects cause $\mathrm{U}^{i}\left(\hat{J}^{i}\right)$ to fall faster than does $\mathrm{U}^{i}\left(\dot{J}^{i}\right)$. The two may cross at some value of $H$. If they do, the potential return migrant return-migrates.

\footnotetext{
${ }^{10}$ Vanderkamp (1968 and 1972), Newbold and Liaw (1994), Bell and Kirwan (1979), and Kirwan and Harrigan (1986). The "one" exception is Newbold and Liaw (1994). But their "bust" is Canada for the entire period 19811986. 1982 was the trough of the "bust," so during most of this period the Canadian economy was expanding. The model predicts high levels of return migration right around 1982. The model also predicts low levels of return migration from 1983-1986 when employment was increasing. So Newbold and Liaw's finding does not contradict the model. (The model also predicts that the onward/return migration ratio will be pro-cyclical. This is not developed in the body of the paper here because only one study has looked at the cyclicality of onward migration. This is Newbold and Liaw (1994), who found the ratio of onward to return migration to be pro-cyclical.)

${ }^{11}$ All studies of return migration find that most of it occurs soon after the initial new move. About 80 percent of return moves occur within a year of the initial new move and almost all occur within five years: Vanderkamp (1968) and (1972), DaVanzo (1981), and DaVanzo and Morrison (1982).
} 


\section{FIGURE 2}

\section{Utility Functions as Hires Decrease}

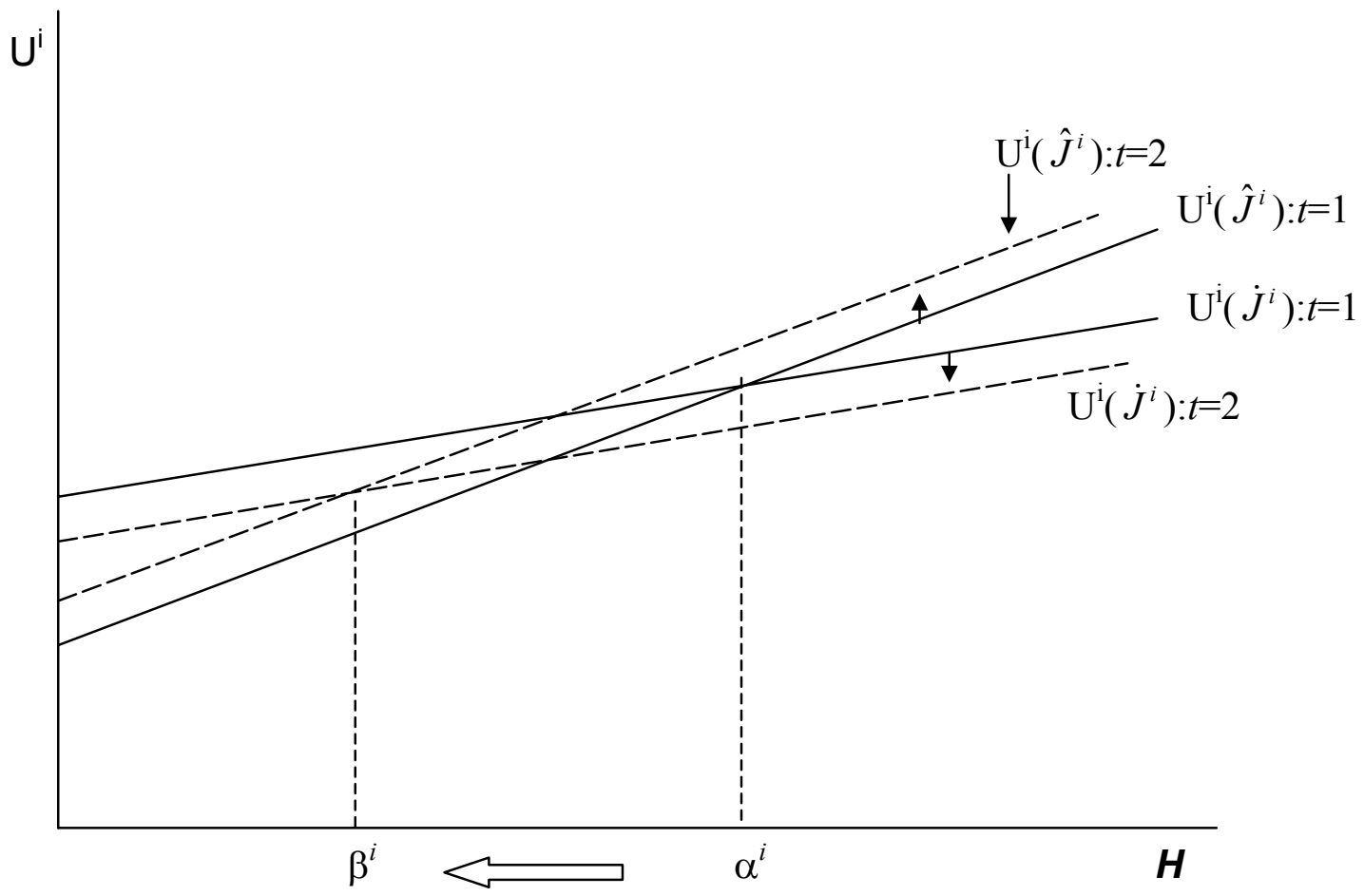

This is shown on Figure 2. Between $t=1$ when the new move was made and $t=2$ when a return move could be made, LSK at $\dot{J}^{i}$ depreciated slightly, causing $\mathrm{U}^{i}\left(\dot{J}^{i}\right)$ to fall at all values of $H$. LSK at $\hat{J}^{i}$ accumulated slightly, causing $\mathrm{U}^{i}\left(\hat{J}^{i}\right)$ to rise at all values of $H$. Nevertheless the two continue to cross at some feasible value of $H . \beta^{i}$ on Figure 2 is the value of $H$ where $\mathrm{U}^{i}\left(\hat{J}^{i}\right)$ crosses $\mathrm{U}^{i}\left(\dot{J}^{i}\right)$ as $H$ falls. During a contraction in period 2, as $H$ falls below $\beta^{i}$ it induces return migration for individual $i$.

Only new migrants are at risk to make a return move. The pro-cyclicality of new migration will have caused a stock of potential return migrants to develop as $H$ rose. That is, recent new migration will have caused there to be a stock of $\beta^{i}$ s to the left of $H$. So as $H$ falls, the volume of return migration rises. Return migration is counter-cyclical.

\subsection{Other Theoretical Effects}

The model also "predicts" the observed pro-cyclicality of quits to search. ${ }^{12}$ As $H$ increases and $q^{i}$ falls, units of $a 1$ are subtracted from A1, and units of $a 2$ are added to A2, in $\mathrm{U}^{i}\left(\dot{J}^{i}\right)$. For some individuals, there are values of $\mathrm{A} 2$, based on expected increases in employment earnings

\footnotetext{
${ }^{12}$ For the pro-cyclicality of quits, see Barron and McCafferty (1977) and Blanchard and Diamond (1990).
} 
after a successful search, and values of $q^{i}$, which will cause quitting-to-search. For these individuals quitting-to-search will be pro-cyclical.

\section{CONCLUSION}

The formal inclusion of location-specific capital and job search in the human capital migration model, and the integration of that model with job-matching, produces a richer theoretical structure. That richer theory retains consistency with the well-known differences in migration propensities between individuals, such as migration rates declining with age, and with the standard cross-section results of migration studies, such as net migration being from lowerearnings to higher-earnings regions. But it is now also consistent with the observed procyclicality of new migration. And it now is not only consistent with, it predicts the observed counter-cyclicality of return migration. Neither the simple human capital model nor the jobmatching/ flows approach alone do both of these.

\section{APPENDIX}

\subsection{The Economics of Jackman and Savouri's Comment}

As a point of fact both earnings and employment rates diverge as the economy contracts. Earnings differentials and employment rate differentials are counter-cyclical. This is why Jackman and Savouri argued that "human capital fails," that "[the human capital model] appears inconsistent with the observation that migration flows often fall when unemployment differentials widen."

In effect, what they're saying is that as $H$ falls, $q^{i}\left(\dot{J}^{i}\right)$ rises by more than does $q^{i}\left(\hat{J}^{i}\right)$. This means that more units of $a 2$ are being subtracted from A2 than are units of $\hat{b} 2$ from $\hat{B} 2$, and fewer units of $a 1$ are being added to $\mathrm{A} 1$ than are units of $\hat{b} 1$ from $\hat{\mathrm{B}} 1$. This can cause the slope of $\mathrm{U}^{i}\left(\dot{J}^{i}\right)$ to be steeper than the slope of $\mathrm{U}^{i}\left(\hat{J}^{i}\right)$, so as $H$ falls $\mathrm{U}^{i}\left(\dot{J}^{i}\right)$ falls more rapidly than $\mathrm{U}^{i}\left(\hat{J}^{i}\right)$. This is the pattern shown in the Appendix Figure. For some individuals, the two may cross at some point, triggering a new move - point $\gamma^{i}$ on Appendix Figure. Aggregating, as $H$ falls, more $\gamma^{i}$ s are crossed. New migration is counter-cyclical.

Jackman and Savouri's comment is based on a model with little or no LSK. While it is plausible that individuals have slopes of $\mathrm{U}^{i}\left(\dot{J}^{i}\right)$ that are steeper than the slopes of $\mathrm{U}^{i}\left(\hat{J}^{i}\right)$, for this to occur A1 cannot be large relative to $\hat{B} 1$. With the full model developed, one sees that for A1 not to be large relative to $\hat{\mathrm{B}} 1$, LSK at $\dot{J}^{i}$ cannot be large. If it is not, it causes the more units of $a 1$ that are being added during a contraction to have little weight, and it can cause new migration to be counter-cyclical. But it is more plausible that, as in this paper, for most individuals LSK at $\dot{J}^{i}$ is large enough to give substantial "weight" to the units of $a 1$ being subtracted during a contraction. This will cause individuals to have slopes of $\mathrm{U}^{i}\left(\hat{J}^{i}\right)$ that are steeper than the slopes of $\mathrm{U}^{i}\left(\dot{J}^{i}\right)$, and it can cause new migration to be pro-cyclical. 
The theory is ambiguous: the Jackman-Savouri pattern may dominate or the pattern described in this paper may dominate. The question can only be answered by observation. The observation of the pro-cyclicality of new migration simply means that many more individuals have large enough values of LSK at $\dot{J}^{i}$ to cause the slope of their $\mathrm{U}^{i}\left(\hat{J}^{i}\right)$ to be steeper than the slope of their $\mathrm{U}^{i}\left(\dot{J}^{i}\right)$ than vice-versa; the pattern described in this paper dominates the JackmanSavouri-assumed pattern for most individuals. Finally I note that the observation of the procyclicality of new migration, understood with the analysis here, adds to the evidence that the size of location-specific capital is an important determinant of migration decisions.

\section{APPENDIX FIGURE}

Jackman-Savouri Functions as Hires Decrease

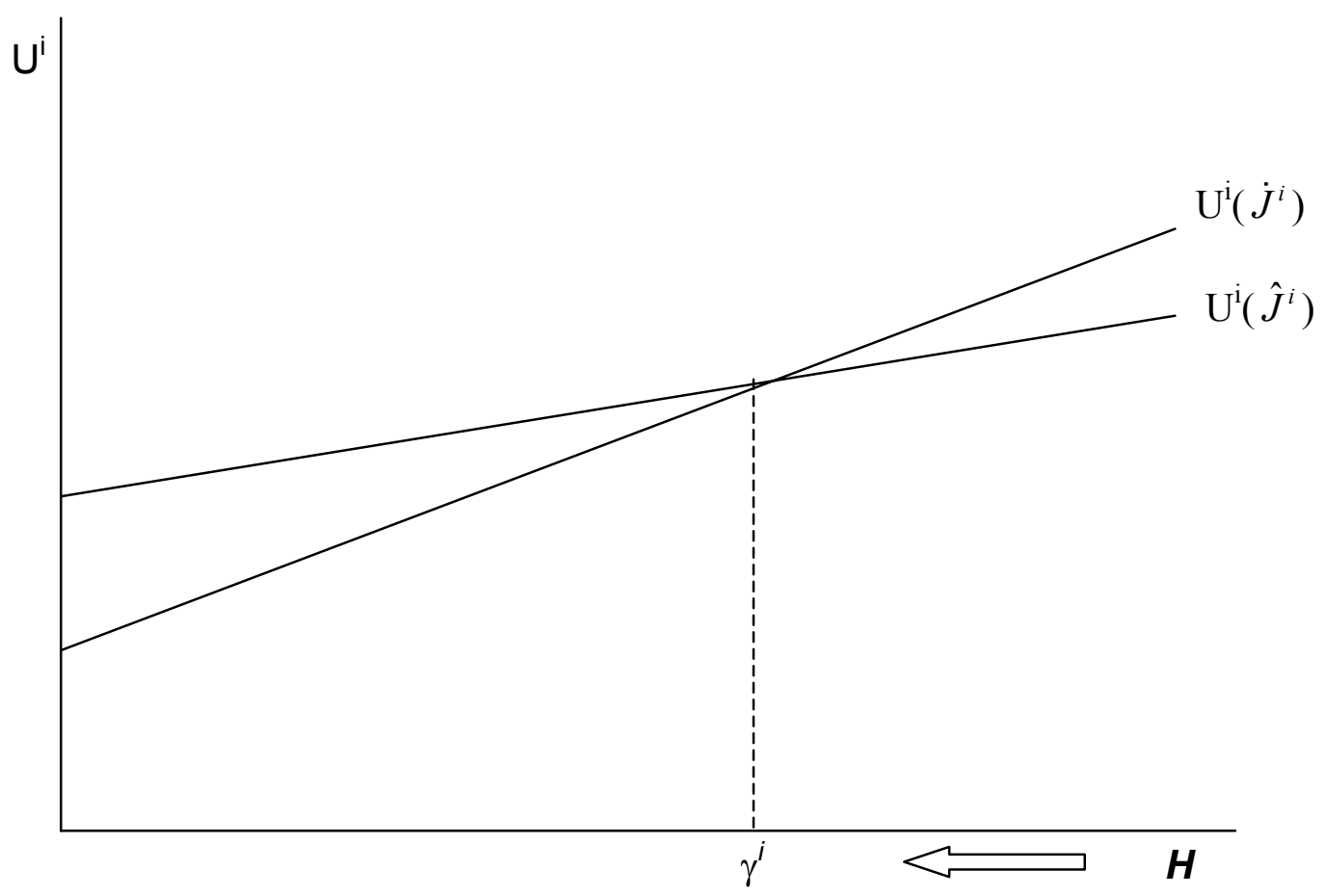

\section{REFERENCES}

Allen, J., 1979. "Information and Subsequent Migration: Further Analysis and Additional Evidence," Southern Economic Journal 45, 1274-1284.

Barron, J.M. and S. McCafferty, 1977. "Job Search, Labor Supply, and the Quit Decision: Theory and Evidence," American Economic Review 67, 683-691.

Bell, D.N.F. and F.X. Kirwan, 1979. "Return Migration in a Scottish Context," Regional Studies $13,101-111$. 
Blanchard, O. and P. Diamond, 1990. "The Cyclical Behavior of the Gross Flows of U.S. Workers," Brookings Papers on Economic Activity 2, 85-155.

Blanchard, O. and P. Diamond, 1992. "The Flows Approach to Labor Markets," American Economic Review 82, 354-359.

Clark, D.E., T.A. Knapp and N.E. White, 1996. "Personal and Location-Specific Characteristics and Elderly Interstate Migration," Growth and Change 27, 327-351.

DaVanzo, J., 1981. "Repeat Migration, Information Costs, and Locational-Specific Capital," Population and Environment 4, 45-73.

DaVanzo, J. and P. Morrison, 1982. "Return and Other Sequences of Migration in the United States," Demography 18, 85-102.

Devine, T. and N. Kiefer, 1990. Empirical Labor Economics: The Search Approach. Oxford University Press: New York.

Eisner, R. and R.H. Strotz, 1961. "Flight Insurance and the Theory of Choice," Journal of Political Economy 69, 355-368.

Greenwood, M., G. Hunt and J. McDowell, 1986. "Migration and Employment Change: Empirical Evidence on the Spatial and Temporal Dimensions of the Linkage," Journal of Regional Science 26, 223-234.

Harris, J.R. and M. Toward, 1970. "Migration, Unemployment and Development: A TwoSector Analysis," American Economic Review 60, 126-142.

Herzog, H.W. and A.M. Schlottmann, 1983. "Moving Back vs. Moving On: The Concept of Home in the Decision to Remigrate," Journal of Regional Science 23, 73-82.

Jackman, R. and S. Savouri. 1992. "Regional Migration in Britain: An Analysis of Gross Flows using NHS Central Register Data,” Economic Journal 102, 1433-1450.

Karni, E., 1985. Decision-Making under Uncertainty: The Case of State-Dependent Preferences. Harvard University Press: Boston.

Kirwan, F. and F. Harrigan, 1986. "Swedish-Finnish Return Migration: Extent, Timing, and Information Flows," Demography 23, 313-327.

McCall, B.P. and J.J. McCall, 1987. “A Sequential Study of Migration and Job Search,” Journal of Labor Economics 5, 452-476.

Mortensen, D.T., 1986. "Models of Search in the Labor Market," in Handbook of Labor Economics. North-Holland: Amsterdam. 
Newbold, K.B., 1997. "Primary, Return and Onward Migration in the U.S. and Canada: Is There a Difference?” Papers in Regional Science 76, 175-198.

Newbold, K.B. and K.L. Liaw, 1994. "Return and Onward Interprovincial Migration through Economic Boom and Bust in Canada, from 1976-81 to 1981-96," Geographical Analysis 26, 228-245.

Padoa-Schioppa, F. (ed.), 1991. Mismatch and Labour Mobility. Cambridge University Press: Cambridge, UK.

Pissarides, C. and J. Wadsworth, 1989. "Unemployment and the Inter-Regional Mobility of Labour," Economic Journal 99, 739-755.

Stigler, G., 1962. "Information in the Labor Market," Journal of Political Economy 81, 11531169.

Vanderkamp, J., 1968. "Interregional Mobility in Canada: A Study of the Time Pattern of Migration," Canadian Journal of Economics 1, 595-608.

Vanderkamp, J., 1972. "Return Migration: Its Significance and Behavior," Western Economic Journal 10, 460-465.

Westerlund, O., 1997. "Employment Opportunities, Wages, and Interregional Migration in Sweden 1970-1989," Journal of Regional Science 37, 55-73.

Yezer, A.M.J. and L. Thurston, 1976. "Migration Patterns and Income Change," Southern Economic Journal 42, 694-702. 